\title{
Research Paper Socio-economic profile and purchase behaviour of elite consumers towards the coconut soft drink Neera
}

See end of the paper for authors' affiliations

Correspondence to :

Sachu Zachariah John

Kerala Livestock

Development Board,

Kulathupuzha (Kerala)

India

Email: Sachuzj@yahoo.com

Paper History :

Received : 11.01.2020;

Revised : 07.02.2020;

Accepted : 14.02 .2020
ABSTRACT : Value addition of agricultural produce is the key to raise farm income. Comprehensive analysis of the probable consumers of the product in terms of socio-economic characters and prepurchase behaviour is a prerequisite for developing marketing plans and strategies. Neera is the sap, extracted from the inflorescence of coconut palm,which is sweet, non-alcoholic and used to quench thirst. The socio-economic profile of the probable consumers, their awareness and the consumption pattern of Neera was studied in three districts of Kerala viz., Trivandrum, Ernakulam and Kozhikode which are placed almost equidistantly along the length of Kerala and representing southern, central and northern zones. The respondents selected were from elite class in these urban centres. Out of 376 consumers interacted 86 per cent were found to be awareand 74 per cent purchasing Neera. Out of those who were aware the product, only 86 per cent were purchasing/using it. Ninety-three per cent of the respondents were graduates or postgraduates. Thirty-four per cent of the respondents were professionals and 17 and 14 per cent were government and private employees. Monthly income of 69 per cent of the respondents ranged from Rs. 0.75 to 1.5 lakhs. The monthly expenditure for Neera was found to be Rs. 407 corresponding to 4.1 and 1.7 percentage to food and food plus non-food expenditure, respectively. The study revealed high market potential for Neera and the marketers may try to take advantage of this situation. Regional differences observed in the awareness may be due to the inappropriate and inadequate distribution of the product to which the marketers should give more attention. Sixty-six per cent of Neera consumers have no specific time or interval for buying Neera because of the nature of the product. Results of the study in dicated that the stock and supply should be regulated for continuous supply of products to the consumers. Appropriate awareness and promotional activities by the marketers may widen the consumer acceptance of Neera.

KEY WORDS : Coconut value addition, Consumer profile, Consumer awareness, Consumption pattern, Neera

HOW TO CITE THIS PAPER : John, Sachu Zachariah and Ushadevi, K.N. (2020). Socio-economic profile and purchase behaviour of elite consumers towards the coconut soft drink Neera . Internat. Res. J. Agric. Eco. \& Stat., 11 (1) : 42-48, DOI : 10.15740/HAS/IRJAES/11.1/42-48. Copyright@ 2020:HindAgri-Horticultural Society. 